\title{
O CICLO PDCA COMO PROPOSTA PARA UMA GESTÃO ESCOLAR EFICIENTE http://dx.doi.org/10.5902/2318133836102
}

\author{
Ronison Oliveira da Silva ${ }^{1}$ \\ Erinaldo Silva Oliveira ${ }^{2}$ \\ Paulo de Sá Filho ${ }^{3}$ \\ Daniel Nascimento-e-Silva ${ }^{4}$
}

\begin{abstract}
Resumo
A escola está inserida como componente da atual sociedade das organizações, sendo um dos componentes do macro sistema organizacional, o que sugere a necessidade de uma boa gestão para que se mantenha sustentável e competitiva. Assim, neste estudo, tem-se por objetivo sugerir o ciclo PDCA como proposta para uma gestão escolar eficiente. Para tanto, utilizou-se o método bibliográfico conceitual desenvolvido por Nascimento-e-Silva (2012), que consiste na formulação de questões norteadoras, coleta de dados em livros e bases de dados, organização e interpretação dos dados para a geração das respostas. Os resultados obtidos permitiram constatar que o ciclo PDCA é uma ferramenta que pode contribuir para a eficiência da gestão escolar, pois fornece uma estrutura para a aplicação de métodos de melhoria contínua alicerçados pela teoria do conhecimento gerencial, bem como pode ser utilizado nas mais diversas realidades e instituições de ensino.

Palavras-chave: PCDA; gestão escolar; administração.
\end{abstract}

\section{THE PDCA CYCLE AS A PROPOSAL FOR AN EFFICIENT SCHOOL MANAGEMENT}

\section{Abstract}

The school is inserted as a component of the current society of organizations, being one of the components of the macro organizational system, which suggests the need for good management so that it remains sustainable and competitive. Thus, this study aims to suggest the PDCA cycle as a proposal for efficient school management. For this, the conceptual bibliographic method developed by Nascimento-e-Silva (2012) was used, which consists of the formulation of guiding questions, data collection in scientific books and databases, organization and interpretation of data for the generation of responses. The results obtained showed that the PDCA Cycle is a tool that contributes to the efficiency of school management, because it provides a framework for the application of methods of continuous improvement based on the theory of managerial knowledge that can be used in the most diverse realities and educational institutions.

Key-word: PCDA; school management; administration.

\footnotetext{
1 Instituto Federal do Amazonas, Brasil. E-mail: ronison.msc@gmail.com.

2 Universidade Federal do Oeste do Pará, Brasil. E-mail: ery-itb@hotmail.com.

3 Serviço Nacional de Aprendizagem Industrial, Brasil. E-mail: prof.paulo@hotmail.com.

4 Instituto Federal de Educação, Ciência e Tecnologia do Amazonas, Brasil. E-mail: danielnss@gmail.com.

\begin{tabular}{|l|l|l|l|l|l|}
\hline Regae: Rev. Gest. Aval. Educ. & Santa Maria & v. 8 & n. 17 & Pub. contínua 2019 & p. 1-13
\end{tabular}
}




\section{Introdução}

ma boa gestão é a responsável pela melhoria dos processos administrativos, financeiros e organizacionais das instituições. Não importa qual seja o tipo ou modelo de organização, quer sejam privadas, governamentais, não governamentais, quer visem ou não o lucro, todas precisam ser bem geridas para que tenham êxito. Logo, para que as instituições possam alcançar a sustentabilidade e se manterem competitivas, processos administrativos devem se fazer presentes (Chiavenato, 2012).

A função social da escola, como espaço da formação da consciência humana (Lima; Zalorenzi; Pinheiro, 2012) não a exclui da atual sociedade de organizações, sendo considerada desta forma mais um importante componente do macro ambiente organizacional, devendo entregar para a sociedade bons resultados para que mantenha sua finalidade. Desta forma, modelos e papéis de gestão devem existir nesses ambientes em diferentes aspectos, como nas definições de funções, projetos, normas e tarefas, disto pressupondo-se a necessidade de organização, a qual é um dos processos do ato de administrar. Questões como estrutura física, projeções, materiais, recursos humanos, processos democráticos de gestão são algumas das demandas presentes na atividade de um gestor escolar e para lidar com essas questões o conhecimento administrativo é de fundamental importância.

Os espaços pedagógicos precisam do entendimento de como podem ser melhor construídos, efetivados, avaliados e modificados para que possam ocorrer mudanças nos processos educativos destes espaços escolares, evoluindo seus enfoques para a participação, descentralização, democracia, responsabilidade e coletividade em seu contexto organizacional. Tudo isso pode ser possível em decorrência de determinada concepção de gestão escolar, pois a maneira como esta é concebida determina como as ações organizacionais serão encaminhadas, se por um processo planejado, organizado e sistematizado, ou por improvisos, arranjos e rearranjos, fatores responsáveis por desperdícios, perdas, fracassos, ineficiencias e maus desempenhos avaliativos.

\section{Administração: conceito geral}

Stoner e Freeman (1999) destacam a Administração como um processo, o qual é uma sequência de etapas inter-relacionadas entre si. Os autores afirmam que são quatro as etapas que compõem a Administração: planejar, organizar, liderar e controlar, nessa ordem. O bom desempenho das fases citadas reduz as incertezas da corporação em conseguir chegar aos seus objetivos. São exatamente os objetivos que movem as organizações e para que eles sejam realizados de forma plena, o trabalho das pessoas deve ser planejado, organizado, liderado e controlado. Para isso necessita-se da ação de certos membros ou equipes da organização, que são responsáveis por uma ou mais dessas etapas do processo. É sobre o trabalho deles que as quatro etapas do processo gerencial devem focar. É importante notar que os autores consideram que liderar é a terceira função administrativa, e não dirigir, como se vê na maioria da literatura.

Maximiano (2000) também entende a Administração como processo decisório, entretanto, sua definição não menciona as quatro funções administrativas. $O$ autor vincula a gestão à tomada de decisão: primeiro deve ocorrer à deliberação do que será feito, depois estas decisões devem ser postas em prática, ou seja, tirar do campo das ideias o 
que foi definido para que se tenha um resultado consistente, de acordo com o que foi anteriormente determinado como alvo. Para o autor, o processo decisório deve se ater sobre dois aspectos: o alcance de objetivos e a utilização de recursos. Todavia, apenas decidir o que se quer não é suficiente. É preciso que um conjunto ordenado de ações seja estabelecido para concretizar o alcance desses objetivos. Estas ações consomem recursos, que por sua vez são os meios que viabilizam a realização de determinado fim. Maximiano (2000) entende que o estabelecimento de objetivos e a previsão de uso dos recursos é o que caracteriza o processo decisório próprio da Administração.

Por sua vez, Chiavenato (1999) e mais recentemente Nascimento-e-Silva (2011), concordam que a Administração é um processo composto por quatro etapas: planejar, organizar, dirigir e controlar. Estas ações devem se ater sobre os recursos organizacionais, pois são eles que possibilitam que os objetivos sejam atingidos de forma efetiva. Nascimento-e-Silva (2011) aponta que os recursos necessitam passar pelas quatro etapas de gestão, como forma de aumentar a perspectiva dos objetivos serem alcançados. Dessa forma, o papel das quatro funções administrativas na utilização dos recursos é o de diminuir, ou se possível for, anular a imprevisibilidade a respeito da consumação dos objetivos. Isso se torna possível com a correta aplicação das quatro partes que compõem o processo de Administração na utilização dos recursos.

Bateman e Snell (2006) também entendem a Administração como processo e condiciona o alcance dos objetivos ao trabalho coordenado entre recursos e pessoas. Dessa forma, estes dois elementos devem ser combinados de forma harmônica para que os objetivos sejam alcançados. Não é possível concretizar os objetivos sem pessoas, muito menos sem recursos. Segundo este autor o sucesso de uma organização tem como requisito básico depender do trabalho feito por pessoas e da existência de recursos.

Para este estudo, Administração é o processo de planejar, organizar, dirigir e controlar o uso dos recursos para atingir os objetivos organizacionais. O processo administrativo é composto por estas quatro etapas, as quais se corretamente executadas podem tornar possível o alcance dos resultados almejados. Desta maneira, os(as) gestores(as) dos recursos institucionais precisam compreender estas quatro etapas para que sua atuação apresente resultados sastifatórios, levando a organização ao alcance da sustentabilidade. Isto sugere que a aplicação destas quatro etapas da administração na gestão das organizações (entre elas as organizações escolares, foco deste estudo) podem melhorar o desempenho e a atuação institucional.

\section{Gestão escolar e suas funções}

Dourado (2012) pondera que a gestão escolar pode ser entendida como a intercessão existente entre recursos, sejam eles de natureza monetária ou de cunho pedagógico. No viés proposto por este autor, a gestão escolar se constitui numa vinculação dos departamentos que formam o todo organizacional escolar, dentre eles: pedagogia, ensino, pesquisa, extensão, compras, logística, corpo docente, materiais e patrimônio e tantos outros. Infere-se que a organização escolar em seu âmbito interno é formada por diversos setores, cada qual com seus objetivos específicos a serem atingidos e cuja consecução contribuem para o sucesso do ambiente escolar como um todo. 
Por sua vez, Nora (2012) enfatiza o aspecto normativo presente na gestão escolar. $\mathrm{Na}$ visão deste autor o administrador escolar, ao elaborar as estratégias de gestão, deve levar em conta a observância aos regramentos e legislações correlatas ao exercício de sua função. Cumpre registrar que em sua definição o autor se utiliza dos termos processo (Stoner, Freeman, 1999; Chiavenato, 2010; Nascimento-e-Silva, 2011) e planejamento (Bateman; Snell, 2006; Nunes; Peccinini, 2012; Ota, 2014), que se constituem em verbetes que descrevem dois pilares conceituais e práticos desta vertente da administração voltada aos espaços estudantis.

Semedo (2011) evidencia o caráter decisório da gestão escolar. Na ótica deste autor a tomada de decisão é um elemento imperioso a ser considerado pelos administradores destes espaços de aprendizagem, com o intuito de assegurar a consecução dos objetivos institucionais a serem atingidos pela escola. Nesse sentido, o papel do diretor escolar trata-se de, pela precisa aplicação das quatro etapas do processo gerencial, assegurar que a instituição para a qual ele trabalha tenha sucesso no conseguimento dos intentos organizacionais. Estes podem ser de natureza pedagógica, a qual tange aspectos conexos a calendário escolar, cumprimento das ementas, trato diário com os docentes do curso, participação nos órgãos colegiados da escola, dentre outros (Inep, 2017). Há também os propósitos de ordem estrutural, que abarcam toda a infra-estrutura (Inep, 2017; Nascimento-e-Silva, 2018) essencial para que a organização possa ofertar os cursos ao seu alunado com a devida qualidade.

Compreende-se que a parte estrutural de uma escola envolve salas de aula, laboratórios e bibliotecas (Inep, 2017), os quais devem estar dotados com todos os recursos (Silva et al. 2016) necessários para o seu funcionamento. Os objetivos escolares ainda podem ser também de ordem legal, a qual envolve a obediência as normas de avaliação dos órgãos regulamentadores da educação (Gatti, 2014; Inep, 2017), uma vez que o bom resultado nestes processos de julgamento asseguram o aporte dos recursos (Silva et al. 2016) em nível federal. Isto reforça a necessidade da instauração de uma gestão escolar consistente, robusta, assertiva e efetiva, tendo como enfoque a consecução dos objetivos estabelecidos, o que pode trazer diferenças incrementais para esses empreendimentos educacionais, tornando-os mais aptos a responder de maneira adequada as demandas presentes no seu ambiente de atuação.

Segundo Paro (1997) a gestão escolar está estruturada em três funções básicas: administrativa, pedagógica e social. Na concepção de gestão escolar, sobre o viés da função administrativa, entende-se que os atores envolvidos deverão entender e aplicar a legislação escolar e as normas administrativas; administrar diversos recursos e zelar dos mesmos; ser responsável pela previsão das despesas e receitas da escola, avaliação e controle dos recursos; dirigir, organizar e administrar as rotinas organizacionais e administrativas. No que tange a função pedagógica, entende-se que essa está ligada a articulação e integração entre os atores envolvidos no processo de ensino-aprendizagem, ou seja, organizar, coordenar e acompanhar as atividades de planejamento; viabilizar a escola como centro de formação continuada dos educadores; dar assistência pedagógica sistematizada aos professores por exemplo. E por último temos a função social, na qual os atores envolvidos terão como responsabilidade organizar atividades que assegurem a 
relação entre escola e comunidade; assumir cada vez mais a função de líder comunitário; promover a comunicação da escola com os pais ou responsáveis, de forma a garantir que as suas necessidades sejam expressas e para que se comprometam com o projeto educacional da escola (Filho, 2006; Libâneo, 2001; Paro, 1997).

Ao vislumbrar todas essas funções nota-se que estão em harmonia e que preconizam os aspectos fundamentais da administração, que são planejamento, organização, direção e controle (Chiavenato, 2011, p. 4). Assim, propomos o ciclo do PDCA como uma proposta de efientização da gestão escolar.

\section{O ciclo PDCA}

Independentemente que a institutição escolar esteja na esfera pública ou na privada, o gestor terá de conhecer o processo gerencial (Stoner, Freeman, 1999; Chiavenato, 2010; Maximiano, 2011; Nascimento-e-Silva, 2011) em todos os seus detalhes e nuances, bem com determinadas ferramentas que tornem a administração destes ambientes ainda mais assertiva, eficiente e produtiva. Uma delas é o cerne deste estudo: o ciclo PDCA.

É importante estabelecer que o ciclo do PDCA são as iniciais das palavras, plan, do, check, e action, que ao traduzir para o português temos diversas variações, tais como: planejar, fazer, verificar e agir ou planejar, direcionar, checar, avaliar. Para este estudo utilizaremos a seguinte variação: planejamento, organização, direção, controle. Inicialmente está ferramenta foi proposta por Deming (1986) e posterior foi difundida por Kotler (1996) e outros (Chiavenato, 2012). Na contemporaneidade encontra-se difundida em inúmeras organizações, nas mais diversas áreas de atuação, contribuindo para uma melhoria na gestão.

\section{O processo de planejamento}

Nascimento-e-Silva (2011) resume o planejamento como uma forma de responder a duas perguntas que se complementam: "onde se pretende chegar?" e "como se chegar lá?". O autor considera imperioso que essas duas respostas sejam o ponto de partida de todas as demais ações do processo gerencial. Dito de outra forma não basta uma organização apenas definir qual é o seu alvo. Isso não é suficiente. Convém dizer também como ela irá fazer para atingir o ponto pretendido. É fundamental que estas duas respostas sejam respondidas com clareza, pois são elas que alicerçam o planejamento e guiam todo o restante do processo gerencial.

Bateman e Snell (2006) entendem que planejamento é um processo centrado em decisões e acrescentam que ele trata-se de um ato racional. Os autores consideram que o planejamento pode ser um ato individual ou coletivo, o qual irá decidir sobre atividades e metas. Isso sugere que o planejamento irá estabelecer tarefas com datas de entrega definidas e que serão supervisionadas para que seja possível avaliar se elas estão sendo feitas ou não de acordo com o que foi planejado. Estas ações acontecerão no futuro, que é o objeto de aplicação do planejamento.

A ideia de planejamento relacionada a futuro também aparece em Nunes e Peccinini (2012) e em Ota (2014). Para os primeiros autores um dos papéis do planejamento é o de se antecipar a estes problemas antes que eles aconteçam na prática, comprometendo o desempenho da organização. Para o segundo o planejamento é uma maneira de projetar no presente em qual estado deseja-se estar num espaço de tempo vindouro, com a ideia 
de que o mesmo seja melhor do que a condição ou estado atual. Ota (2014) considera que as perguntas a serem respondidas no planejamento são "onde?" e "quando?". Isso sugere que a projeção do alvo a ser atingido deve ser focada num objetivo a ser alcançado num espaço temporal futuro (Bateman; Snell, 2006), o que representa a tentativa de avanço ou crescimento da organização.

Assim, planejamento é o processo de tomada de decisões que define os objetivos da organização e as ações necessárias para alcançá-los no futuro. O objetivo é o fim, ou seja, o ponto que se quer alcançar e as ações serão os meios que irão viabilizar o alcance desse objetivo. O resultado esperado com o alcance dos objetivos é um estado posterior melhor do que aquele em que a organização se encontra atualmente.

\section{O processo de organização}

Stoner e Freeman (1999) atribuem à organização o sentido de distribuição, ao destacar três aspectos: o trabalho, a autoridade e os recursos. Dessa forma, organizar o trabalho é estabelecer as tarefas necessárias à realização dos objetivos. A autoridade, por sua vez, diz respeito à liderança, ou seja, a definição das linhas de comando, onde um indivíduo orienta e avalia o trabalho de seus liderados. Os recursos são os meios que tornam possível à organização o alcance dos resultados. Na visão dos autores cabe à função organização a delegação, ou alocação de recursos, o que significa definir onde cada um deles será utilizado para concretizar o alcance dos objetivos organizacionais.

Por sua vez, Maximiano (2011) considera que a função organizar é um processo que se trata de uma sequência lógica de etapas: o objeto de aplicação da função organização são os recursos. Isso sugere que o papel do processo de organização é por em ordem, arrumar, fazer com que os recursos estejam disponíveis e ordenados de forma correta, no seu devido lugar. Organizar, nesse sentido, é trabalhar com exatidão, com correção, com disciplina. A ideia de estrutura ou classificação mencionada pelo autor sugere que os recursos sejam agrupados conforme a sua natureza ou característica, com o intuito de facilitar a sua identificação e organização.

Jung (2012) compreende a organização ligada ao processo produtivo por meio da combinação de recursos. Na visão dessa autora organização é listar tudo aquilo que um sistema de produção necessita para operar e suprir esse sistema com todo o necessário para que ele possa operar de forma plena. Dito de outra forma, organizar é trabalhar com o atendimento das necessidades de um sistema, o qual pode ser uma secretaria, um departamento ou até mesmo uma organização inteira, como uma instituição de ensino. Dessa maneira, a função organizar tem a incumbência de identificar e de suprir tudo o que é necessário para que uma organização possa funcionar. A autora cita alguns exemplos de recursos, como pessoas, insumos e equipamentos. A organização se encarrega de checar a necessidade da utilização destes recursos para assegurar que os seus objetivos possam ser plenamente atingidos.

Dessa forma, organização é o processo que define a utilização de recursos para o alcance dos objetivos organizacionais, sendo o processo uma sequência lógica de etapas que ao final produz alguma coisa e o produto esperado desse processo é o alcance dos 
objetivos por meio dos recursos. Os recursos precisam ser organizados para garantir o máximo de seu aproveitamento, evitar desperdícios e assegurar o bom desempenho da organização.

\section{O processo de direção}

Chiavenato (2010) afirma que dirigir consiste num processo cujo intuito é o de orientar o trabalho das pessoas. Esta orientação ocorre para definir com clareza, aos integrantes de equipes, o que elas devem fazer e como elas devem fazer. Disso depreende-se que a direção reforça a necessidade do líder de equipe exercer o seu nível de influência e autoridade sobre seus liderados, ao comunicar o que a organização espera delas. Nesse sentido, a função da direção é o de guiar as pessoas na realização de suas atividades. A direção deve atuar no sentido de fazer com que os integrantes de equipe concentrem seus esforços naquilo que realmente é necessário para realizar o seu trabalho de forma que o objetivo definido possa ser alcançado.

Nascimento-e-Silva (2011) afirma que a direção deva ser embasada num esquema que trabalhe com o trinômio liderança, motivação e comunicações. A liderança envolve a capacidade do líder em entender de que forma ele deve se vincular aos membros de sua equipe. A motivação é o que conduz a ação e faz com que todos trabalhem em alto nível de performace. Indica o propósito que faz com que os esforços de todos na organização convirjam aos objetivos organizacionais. As comunicações envolvem a partilha de informações e conhecimentos entre os diferentes níveis hierárquicos da organização. Além disso, a comunicação pode ser considerada o meio capaz de integrar os membros de equipe em torno de um mesmo propósito.

Sobral e Peci (2013) entendem que dirigir é gerir pessoas. Tal processo é bastante complexo, uma vez que as pessoas são o recurso mais difícil de administrar. Administrar, nesse sentido, vai além das tarefas de recrutamento, seleção, contratação e retenção de talentos. Significa aglutinar os esforços dos colaboradores, cuja soma dos talentos individuais influi no resultado alcançado pela equipe. A gestão de profissionais feita pela função direção pode representar também vantagem competitiva para a organização, ao diferenciar-se das demais ao manter o quadro de pessoal motivado para realizar suas tarefas.

Nesse sentido, dirigir é o processo de guiar as pessoas na realização de suas atividades para o alcance dos objetivos da organização. Esta função administrativa busca orientar o trabalho das pessoas para que estas executem suas tarefas de acordo com o que foi definido na fase de planejamento e arranjado na fase de organização. Para que as organizações consigam concretizar os seus objetivos, é imperativo que as atividades dos membros de equipe sejam supervisionadas, e isso só é possível por meio da prática da função direção.

\section{O processo de controle}

Chiavenato (2010) indica que a função controle está atrelada ao aspecto da verificação. Dessa forma, o controle possui um caráter comparativo, o qual é representado na análise constante entre o que a organização planejou e o que ela realmente produziu. Esta constante aferição entre o planejado versus realizado indica se a organização está sendo eficiente ou não no alcance dos seus objetivos. Caso sejam 
detectados resultados que não atendam ao que foi planejado, medidas corretivas devem ser tomadas para que a produção da corporação esteja em conformidade com os padrões definidos, e assim alcançar o esperado. Esta definição do autor sugere que ao mensurar o resultado produzido pela organização se avalie se a instituição está ou não no caminho ideal que viabiliza o sucesso organizacional.

Nascimento-e-Silva et al. (2013) indicam o aspecto cíclico da função controle, que encerra o processo gerencial. O objetivo do controle é averiguar o resultado de tudo o que foi produzido anteriormente nas etapas de planejamento, organização e direção. Esta averiguação acontece para que sejam identificadas eventuais falhas no desempenho das atividades, bem como sua posterior correção. Isso permite que a cada vez que o processo gerencial acontecer, o mesmo possa ser refinado o que aumenta o nível de eficiência do mesmo. Dessa forma, a cada nova rodada do processo gerencial, este é aperfeiçoado até funcionar de maneira produtiva e efetiva em sua plenitude.

Tayo (2015) entende que a função controle consiste em mensurar os resultados alcançados pela organização. Esta mensuração permite que a instituição avalie se 0 desempenho do trabalho está inferior, igual ou superior aos parâmetros de avaliação definidos. Quando o resultado está aquém do esperado devem-se investigar as causas do baixo desempenho, bem como medidas corretivas para inverter este quadro negativo. Caso o trabalho realizado atenda aos padrões definidos, deve-se primar pela continuidade deste status. E nas ocasiões em que a performace atingida conseguir ser superior aos indicadores estabelecidos, deve-se reconhecer e premiar os profissionais responsáveis por este resultado pelo excelente desempenho apresentado, o que denota a excelência do trabalho desenvolvido.

O controle é a função que visa a medir os resultados alcançados pela organização e corrigir eventuais desvios aos padrões de desempenho estabelecidos. O controle existe para fazer a comparação entre o trabalho desempenhado e o que foi definido anteriormente nos planos. Caso haja alguma falha entre estes dois parâmetros a mesma deve ser prontamente identificada e corrigida, com o intuito de assegurar que as atividades organizacionais sejam desenvolvidas de acordo com os padrões de desempenho definidos, os quais possibilitam a organização lograr êxito na consecução de seus objetivos organizacionais.

\section{Aplicação do PDCA na gestão escolar}

Para a aplicação do PDCA na gestão escolar serão descritas as ações que devem ser estabelecidas em cada parte do ciclo do PDCA.

A primeira ação nesse processo é a realização do "P". Ressalta-se que os atores envovidos na gestão escolar deverão ter proatividade e visão antecipada, foco em objetivos estratégicos e visão (Chiavenatto, 2011). Somente observando esses aspectos conseguirão elaborar um planejamento que contribua para uma gestão escolar eficiente. É imperioso registrar que o planejamento não torna a organização isenta de passar por alguma adversidade no curso da realização dos intentos definidos, todavia, a exequibilidade do plano torna-se bem mais provável de ser efetuada com resultados positivos. O enfoque do planejamento que integra o PDCA é definir o objetivo a ser 
alcançado no porvir (Nunes; Peccinin, 2012; Ota, 2014), bem como o que terá de ser feito para a concretização de tal feito (Nascimento-e-Silva, 2011). Trata-se do momento de diagnóstico da realidade, definição de metas e determinação de atividades e tarefas a serem cumpridas (Libâneo, 2004).

Um exemplo de propósito a ser atingido por uma organização escolar, o qual será utilizado neste estudo, é a diminuição dos índices de evasão e reprovação por parte do alunado. Para tanto, faz-se necessário que os objetivos sejam quantificados ou descritos em metas (Nascimento-e-Silva, 2017) e etapas para que seja possível efetuar a mensuração do alcance dos mesmos na fase de controle do processo gerencial. Nessa etapa recomenda-se a publicação dos objetivos organizacionais a todos os membros da instituição, visando alinhamento e a transparência de compromissos.

Por sua vez, a inicial "D" correspondente a etapa da organização indica as ações a serem tomadas para que tudo o que foi definido na fase anterior seja realizado conforme o planejado. Albuquerque (2015) destaca que o efeito esperado com a feitura desta etapa do ciclo envolve o uso de recursos (Silva et al. 2016), exemplificados na forma de sistemas - recursos informacionais -, processos (Stoner, Freeman, 1999; Chiavenato, 2010; Nascimento-e-Silva, 2011), e materiais tangíveis que devem ser organizados para fins de obtenção dos objetivos institucionais definidos no início do ciclo PDCA. Depreende-se que nessa fase o resultado esperado deva ser fidedigno ao que foi anteriormente definido na fase correspondente ao planejamento.

Voltando ao exemplo da meta de reduzir a evasão e reprovação de alunos infere-se que uma das ações necessárias ao êxito neste intento seja realizar levantamento com docentes e discentes para compreender quais os processos, razões e fatores - internos e externos - que influenciam diretamente para a existência de resultados negativos nas avaliações realizadas. Trata-se do momento de identificar e procurar sanar ou reduzir as ações ou situações que resultam em atrasos, erros e defeitos no trabalho escolar. Para isso, em muitas situações devem ser instituídos novos programas de treinamento organizacionais. É necessário lembrar que de nada adianta exigir produtividade, melhor desempenho e otimização sem a ministração e comprensão do método que vise a esse fim.

Ja a inicial "C", correspondente ao termo direção, tem por objetivo o monitoramento constante do rendimento das ações desempenhadas na etapa " $D$ ". Albuquerque (2015) aponta para a necessidade do uso de relatórios de observação, enquanto que Nascimento-e-Silva (2017) sugere a instauração de diários de bordo ou scorecards para o devido follow up - acompanhamento - das atividades desempenhadas. Nascimento-eSilva (2017) afirma que não é possível que haja gestão sem a presença de mensurações: são elas que informam a situação da organização no que tange ao atendimento das demandas existentes e necessárias para a materialização dos desígnios organizacionais.

No caso da redução da evasão e reprovação, após a realização do trabalho nas etapas anteriores, esta fase envolve o acompanhamento baseado em indicadores (Nascimento-e-Silva, 2017) que retratem de forma fiel a performace da instituição na busca pelo objetivo pretendido. Caso esses indicadores demonstrem maus resultados cabe ao gestor encorajar e dispor meios que permitam a qualificação e o aperfeiçoamento dos sujeitos envolvidos no processo, visando a melhoria contínua. 
Já o "A", letra que remete ao termo controle, diz respeito às ações corretivas que se façam necessárias. Esta é uma postura diferente do comodismo, que é a de manter o estado atual de coisas com todos os problemas existentes. Entende-se que são estas ações ininterruptas de aperfeiçoamento do ciclo que o torna robusto, hígido e racional, conforme preconizam os princípios basilares da melhoria continua (Graban, 2013). Cabe nessa etapa a reavaliação da própria gestão. É o momento de decidir pela continuidade das ações com resultados positivos e iniciar novo ciclo com posterior replanejamento das ações com resultados negativos ou abaixo do esperado, pois é função da avaliação identificar além das dificuldades as pontecialidades.

Como exemplo podemos citar adaptações, ajustes ou modificações curriculares, visando adequá-lo as necessidades dos discentes. A reavaliação deve compreender, tanto as atividades fins, que são aquelas que referem-se a missão institucional da escola como por exemplo avaliação de ensino, curso, disciplina, desempenho docente, desempenho discente e avaliação da infraestrutura fisica e técnica -, quanto as que se referem as atividades meio, as quais se referem à própria gestão institucional - por exemplo a gestão acadêmica, secretariado e gestão de pessoal (Grochoska, 2014). Compreende-se que estes ajustes realizados são necessários para o sucessivo melhoramento do PDCA, tornando-o uma ferramenta aplicável, sustentável e crível, mediante a correta prática dos princípios aqui demonstrados.

\section{Considerações finais}

Este estudo demonstrou que o ciclo PDCA pode ser aplicável aos mais diversos tipos de organizações, inclusive em organizações escolares, e fornece estrutura para a aplicação de métodos de melhoria alicerçados pela teoria do conhecimento gerencial.

Torna-se, portanto uma excelente ferramenta a ser utilizada pelos gestores para uma gestão escolar eficiente. Isso se deve pelo fato de que seu principal enfoque consiste em auxiliar na concretização dos objetivos das instituições, guiando o gestor escolar e seus pares na propositura de planos e projetos que se adaptem a realidade das instituições de ensino e promovem a melhoria contínua dos mais variados processos em uma Instituição escolar.

Ao insistir na identificação e solução de erros pela permanente qualificação e aperfeiçoamento de sujeitos, recursos, sitemas e processos, demonstra ser uma ferramenta de auxílio na busca do melhor desempenho institucional, tendo o potencial de propor melhores resultados e fortalecer a cultura de construção e reconstrução de saberes, ações e métodos em uma sociedade em que as mudanças são constantes.

\section{Referências}

ALBUQUERQUE, Ananélia Cláudia Rodrigues de Queiroz. Avaliação da aplicação do ciclo PDCA na tomada de decisão em processos industriais. Belém: UFPA, 2015. 107f. Dissertação (Programa de Pós-Graduação em Engenharia de Processos). Universidade Federal do Pará, Belém. Disponível em http://ppgep.propesp.ufpa.br/ARQUIVOS/dissertacoes/Dissertacao2015-PPGEP-MPAnaneliaClaudiaRodriguesdeQueirozAlbuquerque.pdf. Acesso em 10 jan. 2018.

BATEMAN Thomas S.; SNELL Scott A. Administração: novo cenário competitivo. 2. ed. São Paulo: Atlas, 2006. 
CHIAVENATO, Idalberto. Administração, teoria, processo e prática. 4. ed. Rio de Janeiro: Elsevier, 2011.

CHIAVENATO, Idalberto. Administração geral e pública. Baureri: Manole. 2012. 522 p.

CHIAVENATO, Idalberto. Administração nos novos tempos. Rio de Janeiro: Campus, 1999.

CHIAVENATO, Idalberto. Administração dos novos tempos. Rio de Janeiro: Elsevier, 2010.

DEMING, William Edwards. Out of the crisis. Cambrige: MIT Center for advanced Engineering Study, 1986.

DOURADO, Luís Fernandes. Gestão em educação escolar. 4 ed. Cuiabá: UFMT, 2012.

GATTI, Bernardete A. Avaliação: contexto, história e perspectivas. Olh@res, Guarulhos, v. 2, n. 1, 2014, p. 8-26. Disponível em http://www.olhares.unifesp.br/index.php/olhares/article/view/202. Acesso em 10 jan. 2018.

GRABAN, Mark. Hospitais Lean. 2. ed. Bookman: Porto Alegre, 2013.

GROCHOSKA, Marcia Andreia. Organização escolar: perspectivas e enfoques. 2. ed. Curitiba: InterSaberes. 2014.

FILHO, Geraldo Francisco. Administração escolar. analisada no processo histórico. Campinas: Alínea, 2006.

INSTITUTO NACIONAL DE ESTUDOS E PESQUISA EDUCACIONAIS. Instrumento de avaliação de curso de graduação presencial e a distância: reconhecimento, renovação de conhecimento. Brasília: Inep, 2017. Disponível em http://download.inep.gov.br/educacao_superior/avaliacao_cursos_graduacao/instrumentos /2016/instrumento_2016.pdf. Acesso em: 12 jan. 2018.

JUNG, Elaine. Análise do fluxo de peças zincadas: a importância do PCP dentro da organização. ljuí: Unijuí, 2012. 57f. Trabalho de Conclusão de Curso (Departamento de Ciências Administrativas, Contábeis, Econômicas e da Comunicação, curso de Administração), Universidade Regional do Noroeste do Estado do Rio Grande do Sul. Disponível em http://bibliodigital.unijui.edu.br:8080/xmlui/bitstream/handle/123456789/1173/elaineok.pdf? sequence=1. Acesso em 12 jan. 2018.

KOTLER, Philip. Administração de marketing: análise, planejamento, implementação e controle. 4 ed., São Paulo: Atlas, 1996.

LIBÂNEO, José Carlos. Gestão e organização da escola: teoria e prática. 5 ed. Goiânia: Alternativa, 2004.

LIBÂNEO, José Carlos. Organização e gestão da escola: teoria e pratica. 3 ed. Goiânia: Alternativa, 2001.

LIMA, Michele Fernandes; ZANLORENZI, Cláudia Maria Petchak; PINHEIRO, Luciana Ribeiro. A função do currículo no contexto escolar. Curitiba: InterSaberes, 2012.

MAXIMIANO, Antonio César Amaru. Teoria geral da administração: da escola científica à competitividade na economia globalizada. 2. ed. São Paulo: Atlas, 2000.

MAXIMIANO, Antonio César Amaru. Fundamentos de administração: manual compacto para as disciplinas TGA e introdução à administração. 2 ed. São Paulo: Atlas, 2011. 
NASCIMENTO-E-SILVA, Daniel. Compreendendo o processo gerencial. Manaus: Ifam, 2011. Disponível http://www.ifam.edu.br/cms/images/stories/arquivos/planej_estrategico/processo_gerencia I.pdf. Acesso em 12 jan. 2018.

NASCIMENTO-E-SILVA, Daniel. Gerente de infraestrutura. Boa Vista: Roraima em Foco, Ciência e Tecnologia, 2018.

NASCIMENTO-E-SILVA, Daniel. Gestão de organizações de ciência e tecnologia: ferramentas e procedimentos Básicos. Saarbrücken: Novas Edições Acadêmicas, 2017.

NASCIMENTO-E-SILVA, Daniel. Manual de redação para trabalhos acadêmicos: position paper, ensaios teóricos, artigos científicos e questões discursivas. São Paulo: Atlas, 2012.

NASCIMENTO-E-SILVA, Daniel et. al. Proposição de uma sistemática de avaliação de aprendizagem na formação de administradores com base no processo gerencial. Rev. Adm. UFSM, Santa Maria, v. 6, n 4, 2013, p. 640-657. Disponível em https://periodicos.ufsm.br/reaufsm/article/view/5826. Acesso em 12 jan. 2018.

NORA, Sílvia Dalla. A participação da família no processo de gestão educacional. Florianópolis: UFSC, 2012, 42f. Trabalho de conclusão de curso (especialização latosensu em Gestão Educacional). Disponível em https://repositorio.ufsm.br/handle/1/14377. Acesso em 10 jan. 2018.

NUNES, Ana Carla; PECCININI, Alejandro Alvarado. O planejamento estratégico na gestão dos serviços hospitalares no Brasil. CONFERÊNCIA INTERNACIONAL DE ESTRATÉGIA EM GESTÃO, EDUCAÇÃO E SISTEMAS DE INFORMAÇÃO, 1, 2012. Anais ... Goiânia: UEG, 2012, p. 615-631. Disponível em www.anais.ueg.br/index.php/ciegesi/article/view/1157/917. Acesso em 12 jan. 2018.

OTA, Eric Tatsuya. Os desafios para o uso do planejamento estratégico nas organizações públicas: uma visão de especialistas. São Paulo: Fundação Getúlio Vargas, 2014. 212f. Dissertação (Mestrado Profissional em Administração Pública). Escola Brasileira de Administração Pública e de Empresas, Disponível em http://bibliotecadigital.fgv.br/dspace/handle/10438/11825. Acesso em 13 jan. 2018.

PARO, Vitor Henrique. Gestão democrática da escola pública. São Paulo: Ática, 1997.

SEMEDO, Nilton Emanuel Lopes Tavares Paiva. A gestão democrática da escola: do legislado ao instituído: um estudo de caso numa escola secundária cabo-verdiana. Lisboa: Universidade Lusófona de Humanidades e Tecnologia, 2011. 118f. Dissertação (mestrado em Ciências da Educação). Universidade Lusófona de Humanidades e Tecnologia. Disponível em http://recil.grupolusofona.pt/jspui/handle/10437/2900. Acesso em 10 jan. 2018.

SILVA, Harrysson Luiz da et al. Avaliação institucional de prefeituras para desenvolvimento de projetos de gestão social com organizações da sociedade civil de interesse público. Revista de Ciências da Administração, Florianópolis, 2016, p. 124-136. Disponível em https://periodicos.ufsc.br/index.php/adm/article/view/21758077.2016v18n44p124. Acesso em 10 jan. 2018.

SOBRAL, Filipe; PECl, Alketa. Administração: teoria e prática no contexto brasileiro. São Paulo: Personal Education, 2013.

STONER, James A. F; FREEMAN, R. Edwards. Administração. Rio de Janeiro: LTC, 1999. 
TAYO, Michelle Alexandra Morales. Propuesta de um manual de procedimentos internos a la empresa Logika Inteligencia de Mercados. Quito: Pontifícia Universidad Católica, 2015. 160f. Tese (Facultad de Ciencias Administrativas Y Contables), Pontifícia Universidad Católica. Disponível em http://repositorio.puce.edu.ec/bitstream/handle/22000/9108/TESIS\%20FINAL.pdf?sequenc $\mathrm{e}=1$ \&isAllowed=y. Acesso em 12 jan. 2018.

Ronison Oliveira da Silva é estudante no Mestrado Profissional em Educação Profissional e Tecnológica do Ifam. Graduado em Administração pela Faculdade Literatus, MBA em Gerenciamento de Projetos pela Faculdade Maurício de Nassau. Bolsista da Fundação de Amparo à Pesquisa do Estado do Amazonas.

Orcid: https://orcid.org/0000-0003-0709-4081.

Endereço: Rua Monte Calvário, 83 - 69039710 - Manaus - AM - Brasil.

E-mail: ronison.msc@gmail.com.

Erinaldo Silva Oliveira é administrador na Universidade Federal do Oeste do Pará. Estudante no Mestrado Profissional em Educação Profissional e Tecnológica do Ifam.

Orcid: https://orcid.org/0000-0001-8379-0295.

Endereço: Avenida Maranhão, 760 - 68180-410 - Itaituba - PA -Brasil.

E-mail: ery-itb@hotmail.com.

Paulo de Sá Filho é coordenador técnico de cursos no Núcleo Integrado de Educação a Distância do Sesi/Senai/GO. Estudante no Mestrado Profissional em Educação Profissional e Tecnológica do IFGoiano.

Orcid: https://orcid.org/0000-0003-3070-3973.

Endereço: Avenida Araguaia, 1544 - 74645070 - Goiânia - GO - Brasil.

E-mail:prof.paulo@hotmail.com.

Daniel Nascimento-e-Silva é professor no Instituto Federal de Educação, Ciência e Tecnologia do Amazonas.

Orcid: https://orcid.org/0000-0001-9770-575X.

Endereço: Rua André Thevet, 11 - 69098325 - Manaus - AM - Brasil.

E-mail: danielnss@gmail.com.

Recebido em 19 de dezembro de 2018.

Aceito em 9 de janeiro de 2019.

(c) (i) 